\title{
An Inventory Model with Time-Dependent Demand and Limited Storage Facility under Inflation
}

\author{
Neeraj Kumar, ${ }^{1}$ S. R. Singh, ${ }^{2}$ and Rachna Kumari ${ }^{3}$ \\ ${ }^{1}$ Department of Applied Sciences and Humanities, IIMT Engineering College, Meerut 250001, India \\ ${ }^{2}$ Department of Mathematics, D. N (P.G) College, Meerut 250001, India \\ ${ }^{3}$ Department of Mathematics, Meerut College, Meerut 250001, India \\ Correspondence should be addressed to Neeraj Kumar, nkneerajkapil@gmail.com
}

Received 16 March 2012; Revised 6 September 2012; Accepted 7 September 2012

Academic Editor: Lars Mönch

Copyright (C) 2012 Neeraj Kumar et al. This is an open access article distributed under the Creative Commons Attribution License, which permits unrestricted use, distribution, and reproduction in any medium, provided the original work is properly cited.

The main objective of this paper is to develop a two-warehouse inventory model with partial backordering and Weibull distribution deterioration. We consider inflation and apply the discounted cash flow in problem analysis. The discounted cash flow (DCF) and optimization framework are presented to derive the optimal replenishment policy that minimizes the total present value cost per unit time. When only rented or own warehouse model is considered, the present value of the total relevant cost is higher than the case when two-warehouse is considered. The results have been validated with the help of a numerical example. Sensitivity analysis with respect to various parameters is also performed. From the sensitivity analysis, we show that the total cost of the system is influenced by the deterioration rate, the inflation rate, and the backordering ratio.

\section{Introduction}

Deterioration is the change, damage, decay, spoilage, evaporation, obsolescence, pilferage, and loss of utility or loss of marginal value of a commodity that results in decreasing usefulness from the original one. Most products such as medicine, blood, fish, alcohol, gasoline, vegetables, and radioactive chemicals have finite shelf life and start to deteriorate once they are replenished. In addition, for certain types of commodities, deterioration is usually observed during their normal storage period. In most of the inventory models it is unrealistically assumed that during stockout either all demand is backlogged or all is lost. In reality often some customers are willing to wait until replenishment, especially if the wait will be short, while others are more impatient and go elsewhere. The backlogging rate depends 
on the time to replenishment the longer customers must wait, the greater the fraction of lost sales.

The classical inventory models usually assume that the available warehouse has unlimited capacity. In many practical situations, there exist many factors like temporary price discounts making retailers buy a capacity of goods exceeding their own warehouse $(O W)$. In this case, retailers will either rent other warehouses or rebuild a new warehouse. However, from economical point of views, they usually choose to rent other warehouses. Hence, an additional storage space known as rented warehouse $(R W)$ is often required due to limited capacity of showroom facility. In recent years, various researchers have discussed a twowarehouse inventory system. This kind of system was first proposed by Hartely [1]. In this system, it was assumed that the holding cost in $R W$ is greater than that in $O W$. By assuming constant demand rate, Sarma [2] developed a deterministic inventory model for a single deteriorating item with shortages and two levels of storage. Pakkala and Achary [3] extended the two-warehouse inventory model for deteriorating items with finite replenishment rate and shortages. Besides, the ideas of time-varying demand for deteriorating items with two storage facilities were considered by Benkherouf [4] and Bhunia and Maiti [5].

Most research on inventory do not consider the time value of money. This is unrealistic, since the resource of an enterprise depends very much on time value of money and this is highly correlated to the return of investment. Therefore, taking into account the time value of money should be critical especially when investment and forecasting are considered. Buzacott [6] was the first author to include the concept of inflation in inventory modeling. He developed a minimum cost model for a single-item inventory with inflation. Misra [7] simultaneously considered both the inflation and the time value of money for internal as well as external inflation rate and analyzed the influence of interest rate and inflation rate on replenishment strategy. Chandra and Bahner [8] extended the result in Misra's [7] model to allow for shortages. Sarker and Pan [9] assumed a finite replenishment model and analyzed the effects of inflation and time value of money on order quantity in which shortages were allowed. Hariga [10] extended the study to analyze the effects of inflation and time value of money on an inventory model with time-dependent demand rate and shortages. Bose et al. [11] developed an EOQ model for deteriorating items with linear time-dependent demand rate and shortages under inflation and time discounting. Van Delft and Vial [12] proposed a simple economic order quantity model for inventory with a short and stochastic lifetime. Their approach was performed in the framework of the total discounted cost criterion. Moon and Lee [13] discussed different types of inventory models with the effects of inflation. For the first time the effect of inflation in two-warehouse system was discussed by Yang [14]. In her study, she considered the constant rate of deterioration in both warehouses with constant demand rate and shortages were completely backlogged. Wee et al. [15] developed twowarehouse inventory model with partial backordering and Weibull distribution deterioration under inflation. In their study, they assumed that the demand and backlogging rate are constant but is not always the case in real life. Yang [16] presented two-warehouse partial backlogging inventory models for deteriorating items under inflation with constant demand rate. Dey et al. [17] developed two storage inventory problems with inflation and time value of money. Ghosh and Chakrabarty [18] suggested an order-level inventory model with two levels of storage for deteriorating items and shortages were fully backlogged. Recently, Jaggi and Verma [19] developed a two-warehouse inventory model with linear trend in demand under the inflationary conditions. In their model, shortage was allowed and completely backlogged. Patra [20] presented a two-warehouse inventory model with constant rate of deterioration and time value of money. In his model, shortages are completely backlogged. 
Singh et al. [21] presented a deterministic two-warehouse inventory model for deteriorating items with partial backlogging. Yang [22] extended Yang [16] model to incorporate threeparameter Weibull deterioration distribution with constant demand.

It has been observed that most researchers on inventory models do not consider time-varying rate of deterioration, inflation, and partial backordering simultaneously. Since this phenomenon is not uncommon in real life, the researchers should also incorporate them in their problem development. In this paper, the researcher has considered a twowarehouse inventory system for deteriorating items. Here, shortages are allowed and partially backlogged. The holding cost at $R W$ is higher as compared to $O W$. The rate of deterioration in both warehouses is different and follows a two-parameter Weibull distribution. Further, this study takes inflation and applies the discounted cash flow (DCF) approach for problem analysis. In this study, the demand rate is exponentially increasing with time and shortages are partially backlogged with exponential backlogging rate. The discounted cash flow and optimization framework are presented to derive the optimal replenishment policy that minimizes the total present value cost. A numerical example and sensitivity analysis are presented to illustrate all the models. When only rented or own warehouse is considered, the present value of the total relevant cost is higher than the case when two-warehouse model is considered. From the sensitivity analysis, the total cost of the system is influenced by the deterioration rate, the inflation rate, and the backordering ratio.

\section{Assumptions and Notations}

In developing the mathematical models of the inventory system for this study, the following common assumptions were used.

(1) Demand rate is known and is equal to $a e^{b t}$, where $a>1$ and $0<b<1(a>b)$ are constants.

(2) Shortages are allowed and backlogging rate is $e^{-\lambda t}$, when inventory is in shortage. The backlogging parameter $\lambda$ is positive constant and $0<\lambda \ll 1$.

(3) Deterioration of the item follows a two-parameter Weibull distribution.

(4) Deterioration occurs as soon as items are received into inventory.

(5) There is no replacement or repair of deteriorating items during the period under consideration.

(6) Product transactions are followed by instantaneous cash flow.

(7) The holding costs in $R W$ are higher than those in $O W$.

(8) The OW has a fixed capacity of $W$ units and the RW has unlimited capacity.

(9) Lead time is zero and initial inventory level is zero.

(10) The replenishment rate is infinite.

The following notations were used throughout the paper.

$W$ : Capacity of $O W$

$\alpha$ : Scale parameter of the deterioration rate in $O W$

$\beta$ : Shape parameter of the deterioration rate in $O W$

$g$ : Scale parameter of the deterioration rate in $R W, \alpha>g$ 
$h$ : Shape parameter of the deterioration rate in $R W$

$r$ : Inflation rate

$A$ : Ordering cost per order ( $\$$ /order)

$H$ : Holding cost per unit per unit time in $O W$ (\$/unit/unit time)

$F$ : Holding cost per unit per unit time in $R W$ (\$/unit/unit time), $F>H$

$s$ : Shortage cost per unit time (\$/unit/unit time)

$\pi$ : Shortage cost for lost sales per unit (\$/unit)

$C$ : Item cost per unit (\$/unit)

$Q_{0}$ : The order quantity in $O W$

$Q_{r}$ : The order quantity in $R W$

$I_{r}$ : Maximum inventory level in $R W$

$T_{2}$ : Time with positive inventory in $R W$

$T_{1}+T_{2}$ : Time with positive inventory in $O W$

$T_{3}$ : Time when shortage occurs in $\mathrm{OW}$

$T$ : Length of the cycle, $T=T_{1}+T_{2}+T_{3}$

$I_{0 i}\left(t_{i}\right)$ : Inventory level in $O W$ at time $t_{i}, \quad 0 \leq t_{i} \leq T_{i}, i=1,2,3$

$I_{r}\left(t_{1}\right)$ : Inventory level in $R W$ at time $t_{1}, 0 \leq t_{1} \leq T_{1}$

TUC: The present value of the total relevant cost per unit time.

The rate of deterioration is given as follows.

$t$ : Time to deterioration, $t>0$

$f(t)$ : Probability density function (pdf) of product life

$F(t)$ : Cumulative distribution function (cdf) of product life

$R(t)$ : Reliability

$Z(t)$ : Instantaneous rate of deterioration.

From the reliability theory, one has $R(t)=1-F(t), Z(t)=f(t) / R(t)$, and $R(0)=1$. The product life $t$ is assumed to follow a two-parameter Weibull distribution. The researcher has assumed $x$ as scale parameter, $y$ as shape parameter, and $x, y>0$. Then one has

$$
\begin{gathered}
f(t)=x y t^{y-1} e^{-x t^{y}}, \\
F(t)=\int_{-\infty}^{t} f(t) d t=1-e^{-x t^{y},} \\
R(t)=1-F(t)=e^{-x t^{y}}, \\
Z(t)=\frac{f(t)}{R(t)}=\frac{x y t^{y-1} e^{-x t^{y}}}{e^{-x t^{y}}}=x y t^{y-1} .
\end{gathered}
$$

The instantaneous rate of deterioration $Z(t)=x y t^{y-1}$ is used in the following model development. 
When $y>1$, deteriorating rate increases with time. When $y<1$, deteriorating rate decreases with time. And when $y=1$, deteriorating rate is constant. The two-parameter Weibull distribution reduces to the exponential distribution.

\section{Formulation and Solution of the Model}

The $O W$ inventory system in Figure 1 can be divided into three phases depicted by $T_{1}$ to $T_{3}$. For each replenishment, a portion of the replenished quantity is used to backorder shortage, while the rest enters the system. $W$ units of items are stored in the $O W$ and the rest is dispatched to the $R W$. The $R W$ is therefore utilized only after $O W$ is full, but stocks in $R W$ are dispatched first. Stock in the $R W$ depletes due to demand and deterioration until it reaches zero. During that time, the inventory in $O W$ decreases due to deterioration only. The stock in $O W$ depletes due to the combined effect of demand and deterioration during time $T_{2}$. During the time $T_{3}$, both warehouses are empty, and part of the shortage is backordered in the next replenishment.

The $O W$ inventory system can be represented by the following differential equations

$$
\begin{gathered}
I_{01}^{\prime}\left(t_{1}\right)=-\alpha \beta t_{1}^{\beta-1} I_{01}\left(t_{1}\right), \quad 0 \leq t_{1} \leq T_{1}, \\
I_{02}^{\prime}\left(t_{2}\right)=-a e^{b t_{2}}-\alpha \beta t_{2}^{\beta-1} I_{02}\left(t_{2}\right), \quad 0 \leq t_{2} \leq T_{2}, \\
I_{03}^{\prime}\left(t_{3}\right)=-e^{-\lambda t_{3}} a e^{b t_{3}}=-a e^{(b-\lambda) t_{3}}, \quad 0 \leq t_{3} \leq T_{3} .
\end{gathered}
$$

The first-order differential equations can be solved using the boundary conditions, $I_{01}(0)=$ $W, I_{01}\left(T_{1}\right)=I_{02}(0)=W e^{-\alpha T_{1}^{\beta}}$, and $I_{03}(0)=0$, one has

$$
\begin{gathered}
I_{01}\left(t_{1}\right)=W e^{-\alpha t_{1}^{\beta}}, \quad 0 \leq t_{1} \leq T_{1}, \\
I_{02}\left(t_{2}\right)=\frac{W e^{-\alpha T_{1}^{\beta}}-a \int_{0}^{t_{2}} e^{b u+\alpha u^{\beta}} d u}{e^{\alpha t_{2}^{\beta}}}, \quad 0 \leq t_{2} \leq T_{2}, \\
I_{03}\left(t_{3}\right)=\frac{a}{b-\lambda}\left(1-e^{(b-\lambda) t_{3}}\right), \quad 0 \leq t_{3} \leq T_{3} .
\end{gathered}
$$

The $R W$ inventory system can be represented by the following differential equation

$$
I_{r}^{\prime}\left(t_{1}\right)=-a e^{b t_{1}}-g h t_{1}^{h-1} I_{r}\left(t_{1}\right), \quad 0 \leq t_{1} \leq T_{1}
$$

The first-order differential equation can be solved using the boundary condition, $I_{r}(0)=I_{r}$, one has

$$
I_{r}\left(t_{1}\right)=\frac{I_{r}-a \int_{0}^{t_{1}} e^{b u+g u^{h}} d u}{e^{g t_{1}^{h}}}, \quad 0 \leq t_{1} \leq T_{1}
$$




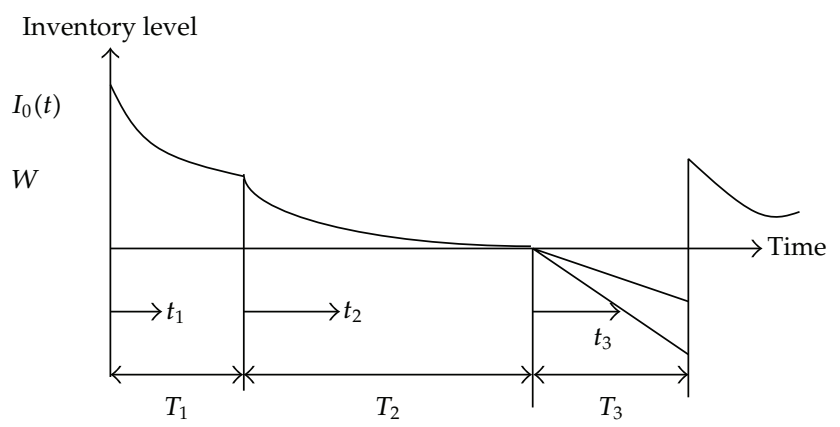

Figure 1: Graphical representation of the $O W$ inventory system.

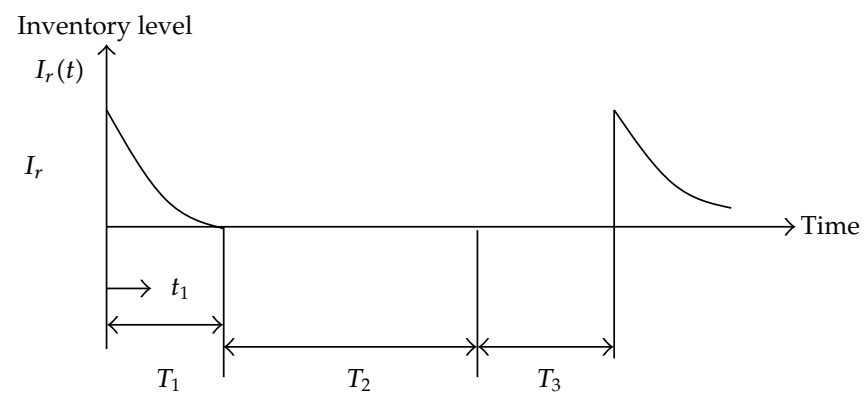

Figure 2: Graphical representation of the $R W$ inventory system.

where

$$
I_{r}=a \int_{0}^{T_{1}} e^{b u+g u^{h}} d u=a\left(T_{1}+\frac{b T_{1}^{2}}{2}+\frac{g T_{1}^{h+1}}{h+1}\right)
$$

(1) From Figure 1, replenishment is made at $t_{1}=0$, the present worth ordering cost is

$$
O R=A .
$$


(2) Inventory occurs during $T_{1}$ and $T_{2}$ time periods. The present worth inventory cost in $O W$ is

$$
\begin{aligned}
& H O_{O W}=H\left\{\int_{0}^{T_{1}} I_{01}\left(t_{1}\right) e^{-r t_{1}} d t_{1}+\int_{0}^{T_{2}} I_{02}\left(t_{2}\right) e^{-r\left(T_{1}+t_{2}\right)} d t_{2}\right\} \\
&=H W\left(T_{1}-\frac{\alpha T_{1}^{\beta+1}}{\beta+1}-\frac{r T_{1}^{2}}{2}\right)+H[ W\left(1-\alpha T_{1}^{\beta}-r T_{1}\right) T_{2} \\
&+\frac{\left(-W-a+a r T_{1}\right) T_{2}^{2}}{2}+\left(a r-\frac{a b}{2}+\frac{a b \alpha}{2}\right) \frac{T_{2}^{3}}{3} \\
&+\frac{a b r T_{2}^{4}}{8}-\frac{W \alpha T_{2}^{\beta+1}}{(\beta+1)}+\frac{a \alpha \beta T_{2}^{\beta+2}}{(\beta+1)(\beta+2)} \\
&\left.+\frac{a b \alpha T_{2}^{\beta+3}}{2(\beta+3)}\right] .
\end{aligned}
$$

(3) Shortages occur during $T_{3}$ time period. The present worth shortage cost in $O W$ is

$$
S C=s\left\{\int_{0}^{T_{3}}\left[-I_{03}\left(t_{3}\right)\right] e^{-r\left(T_{1}+T_{2}+t_{3}\right)} d t_{3}\right\}=s a\left[\frac{\left(1-r T_{1}-r T_{2}\right) T_{3}^{2}}{2}-\frac{r T_{3}^{3}}{3}\right] .
$$

(4) Lost sales occur during $T_{3}$ time period. The present worth lost sale cost in $\mathrm{OW}$ is

$$
L S=\pi\left\{\int_{0}^{T_{3}}\left(1-e^{-\lambda t_{3}}\right) a e^{b t_{3}} e^{-r\left(T_{1}+T_{2}+t_{3}\right)} d t_{3}\right\}=\pi a \lambda\left[\frac{\left(1-r T_{1}-r T_{2}\right) T_{3}^{2}}{2}-\frac{r T_{3}^{3}}{3}\right] .
$$

(5) Replenishment occurs at $t=0$ and $t=T_{1}+T_{2}+T_{3}=T$. The item cost includes loss due to deterioration as well as the cost of the item sold. The present worth item cost in $O W$ is

$$
I T_{0}=C\left(W-\frac{a}{b-\lambda}\left(1-e^{(b-\lambda) T_{3}}\right) e^{-r\left(T_{1}+T_{2}+T_{3}\right)}\right)=C\left\{W+a T_{3}\left[1-r\left(T_{1}+T_{2}+T_{3}\right)\right]\right\} .
$$

(6) From Figure 2, inventory occurs during $T_{1}$ time periods. The present worth inventory cost in $R W$ is

$$
\begin{aligned}
H O_{R W} & =F\left\{\int_{0}^{T_{1}} I_{r}\left(t_{1}\right) e^{-r t_{1}} d t_{1}\right\} \\
& =F a\left[\frac{T_{1}^{2}}{2}+\frac{b T_{1}^{3}}{3}-\frac{r T_{1}^{3}}{6}-\frac{b r T_{1}^{4}}{8}+\frac{g h T_{1}^{h+2}}{(h+1)(h+2)}-\frac{b g T_{1}^{h+3}}{(h+1)(h+3)}\right] .
\end{aligned}
$$


(7) Replenishment occurs at $t=0$. The item cost therefore includes loses due to deterioration as well as the cost of the item sold. The present worth cost in $R W$ is

$$
I T_{r}=C I_{r}=C\left(a \int_{0}^{T_{1}} e^{b u+g u^{h}} d u\right)=C a\left[T_{1}+\frac{b T_{1}^{2}}{2}+\frac{g T_{1}^{h+1}}{h+1}\right] .
$$

(8) The present value of the total relevant cost during the cycle is

$$
\begin{aligned}
\operatorname{TUC}\left(T_{1}, T_{2}, T_{3}\right)= & \frac{1}{T}\left\{O R+\left(H O_{O W}+H O_{R W}\right)+S C+L S+\left(I T_{0}+I T_{r}\right)\right\} \\
\operatorname{TUC}\left(T_{1}, T_{2}, T_{3}\right)=\frac{1}{T}\{A+ & H W\left(T_{1}-\frac{\alpha T_{1}^{\beta+1}}{\beta+1}-\frac{r T_{1}^{2}}{2}\right) \\
+ & H\left[W\left(1-\alpha T_{1}^{\beta}-r T_{1}\right) T_{2}+\frac{\left(-W-a+a r T_{1}\right) T_{2}^{2}}{2}\right. \\
+ & \left(a r-\frac{a b}{2}+\frac{a b \alpha}{2}\right) \frac{T_{2}^{3}}{3}+\frac{a b r T_{2}^{4}}{8}-\frac{W \alpha T_{2}^{\beta+1}}{(\beta+1)} \\
+ & \left.\frac{a \alpha \beta T_{2}^{\beta+2}}{(\beta+1)(\beta+2)}+\frac{a b \alpha T_{2}^{\beta+3}}{2(\beta+3)}\right] \\
+ & s a\left[\frac{\left(1-r T_{1}-r T_{2}\right) T_{3}^{2}}{2}-\frac{r T_{3}^{3}}{3}\right] \\
+ & \pi a \lambda\left[\frac{\left(1-r T_{1}-r T_{2}\right) T_{3}^{2}}{2}-\frac{r T_{3}^{3}}{3}\right] \\
+ & C\left[W+a T_{3}\left(1-r\left(T_{1}+T_{2}+T_{3}\right)\right)\right] \\
+ & F a\left[\frac{T_{1}^{2}}{2}+\frac{b T_{1}^{3}}{3}-\frac{r T_{1}^{3}}{6}-\frac{b r T_{1}^{4}}{8}+\frac{g h T_{1}^{h+1}}{(h+1)(h+2)}-\frac{b g T_{1}^{h+3}}{(h+1)(h+2)}\right] \\
+ & \left.C a\left(T_{1}+\frac{b T_{1}^{2}}{2}+\frac{g T_{1}^{h+1}}{h+1}\right)\right\} .
\end{aligned}
$$

The optimization problem can be formulated as:

Minimize : $\operatorname{TUC}\left(T_{1}, T_{2}, T_{3}\right)$,

Subject to: $T_{1} \geq 0, T_{2} \geq 0, T_{3} \geq 0$. 


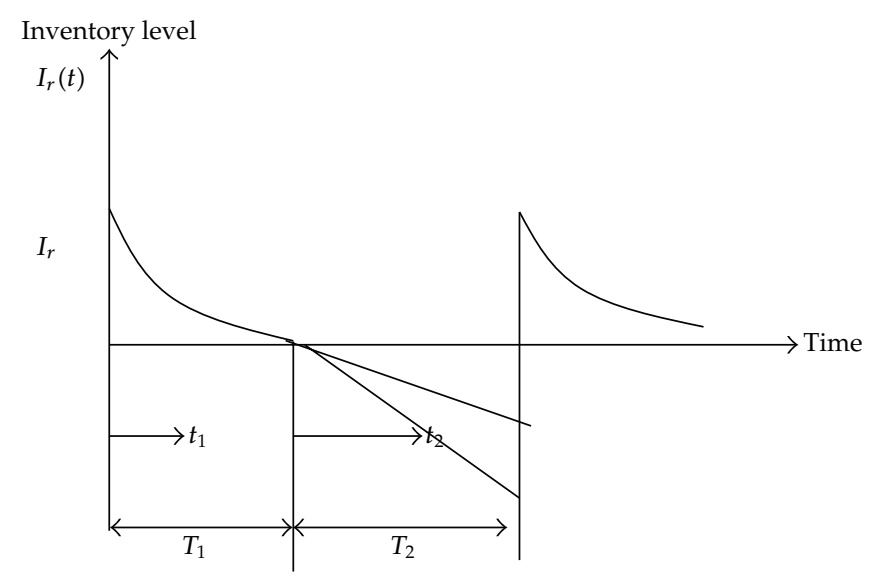

Figure 3: Graphical representation of the $R W$ inventory system (one warehouse-rented).

In the above expression, TUC is the objective function which we have to minimize, which is the function of $T_{1}, T_{2}$, and $T_{3}$. To minimize the objective function, the solution methodology is presented in Section 6 .

\section{When the System Has Only Rented Warehouse (RW)}

Figure 3 shows the graphical representation of the $R W$ inventory system having only rented warehouse. The $R W$ inventory level function during $T_{1}$ and $T_{2}$ time periods is similar to (3.6) and (3.4). The ordering cost and holding cost of the system are similar to (3.8) and (3.13).

Shortages occur during $T_{2}$ time period. The present worth shortage cost in $R W$ is

$$
S C=s\left\{\int_{0}^{T_{2}}\left(-\frac{a}{b-\lambda}\left(1-e^{(b-\lambda) t_{2}}\right)\right) e^{-r\left(T_{1}+t_{2}\right)} d t_{2}\right\}=s a\left[\frac{\left(1-r T_{1}\right) T_{2}^{2}}{2}-\frac{r T_{2}^{3}}{3}\right] .
$$

Lost sales occur during $T_{2}$ time period. The present worth lost sales cost in $R W$ is

$$
L S=\pi\left\{\int_{0}^{T_{2}}\left(1-e^{-\lambda t_{2}}\right) a e^{b t_{2}} e^{-r\left(T_{1}+t_{2}\right)} d t_{2}\right\}=\pi a \lambda\left\{\frac{\left(1-r T_{1}\right) T_{2}^{2}}{2}-\frac{r T_{2}^{3}}{3}\right\}
$$

Replenishment occurs at $t=0$ and $t=T_{1}+T_{2}=T$. The item cost therefore includes loss due to deterioration as well as the cost of the item sold. The present worth item cost in $R W$ is

$$
I T_{r}=C\left[I_{r}-\frac{a}{b-\lambda}\left(1-e^{(b-\lambda) T_{2}}\right) e^{-r\left(T_{1}+t_{2}\right)}\right]=C a\left[\left(T_{1}+\frac{b T_{1}^{2}}{2}+\frac{g T_{1}^{h+1}}{h+1}\right)+T_{2}\left(1-r\left(T_{1}+t_{2}\right)\right)\right] .
$$


The order quantity in $R W$ per order is

$$
Q_{r}=I_{r}-\frac{a}{b-\lambda}\left(1-e^{(b-\lambda) T_{2}}\right)=a\left(T_{1}+\frac{b T_{1}^{2}}{2}+\frac{g T_{1}^{h+1}}{h+1}\right)+a T_{2}
$$

Noting that $T=T_{1}+T_{2}$, the total present value of the total relevant cost per unit time during the cycle is the sum of ordering cost, holding cost, shortage cost, lost sale cost, and item cost.

$$
\begin{gathered}
\operatorname{TUC}_{r}\left(T_{1}, T_{2}\right)=\frac{1}{T}\left\{O R+H O_{R W}+S C+L S+I T_{r}\right\}, \\
\operatorname{TUC}_{r}\left(T_{1}, T_{2}\right)=\frac{1}{T}\left\{A+F a\left[\frac{T_{1}^{2}}{2}+\frac{b T_{1}^{3}}{3}-\frac{r T_{1}^{3}}{6}-\frac{b r T_{1}^{4}}{8}+\frac{g h T_{1}^{h+2}}{(h+1)(h+2)}-\frac{b g T_{1}^{h+3}}{(h+1)(h+3)}\right]\right. \\
+s a\left[\frac{\left(1-r T_{1}\right) T_{2}^{2}}{2}-\frac{r T_{2}^{3}}{3}\right]+\pi a \lambda\left\{\frac{\left(1-r T_{1}\right) T_{2}^{2}}{2}-\frac{r T_{2}^{3}}{3}\right\} \\
\left.+C a\left[\left(T_{1}+\frac{b T_{1}^{2}}{2}+\frac{g T_{1}^{h+1}}{h+1}\right)+T_{2}\left(1-r\left(T_{1}+t_{2}\right)\right)\right]\right\} .
\end{gathered}
$$

In the above expression, $\mathrm{TUC}_{r}$ is the objective function which we have to minimize, which is the function of $T_{1}$ and $T_{2}$. To minimize the objective function, the solution methodology is presented in Section 6.

\section{When the System Has Only Own Warehouse (OW)}

Figure 4 shows the graphical representation of the $O W$ inventory system having only own warehouse. The $O W$ inventory level function during $T_{1}$ and $T_{2}$ time periods is similar to (3.6) and (3.4). The ordering cost, holding cost, shortage cost, and lost sale cost of the system are similar to (3.8), (3.9), (3.10), and (3.11). The order quantity in $O W$ per order is

$$
Q_{0}=W-\frac{a}{b-\lambda}\left(1-e^{(b-\lambda) T_{2}}\right)=W+a T_{2} .
$$

Replenishment occurs at $t=0$ and $t=T_{1}+T_{2}$. The item cost therefore includes loss due to deterioration as well as the cost of the item sold. The present worth item cost in $O W$ is

$$
I T_{r}=C\left(W-\frac{a}{b-\lambda}\left(1-e^{(b-\lambda) T_{2}}\right) e^{-r\left(T_{1}+T_{2}\right)}\right)=C\left\{W+a T_{2}\left[1-r\left(T_{1}+T_{2}\right)\right]\right\}
$$




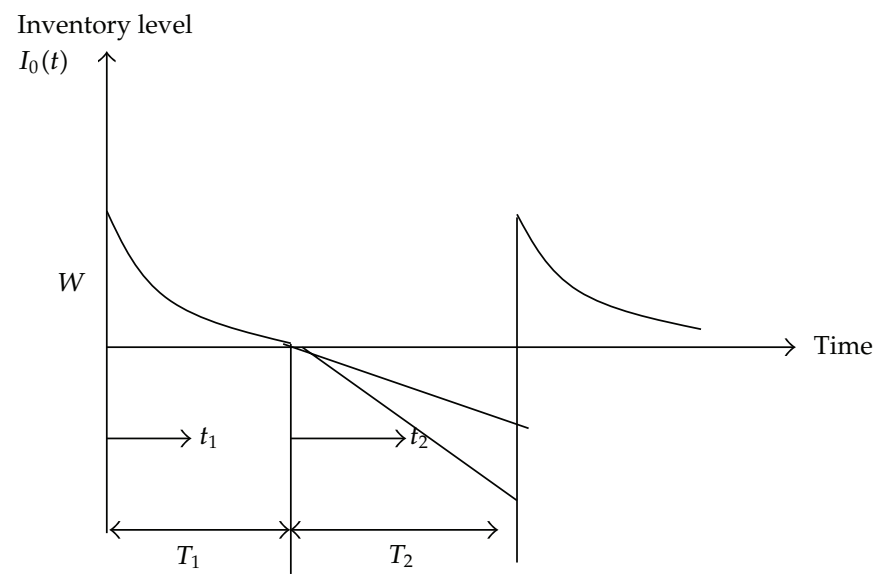

Figure 4: Graphical representation of the $O W$ inventory system (one warehouse-own).

Noting that $T=T_{1}+T_{2}$, the total present value of the total relevant cost per unit time during the cycle is the sum of ordering cost, holding cost, shortage cost, lost sale cost, and item cost

$$
\begin{gathered}
\quad \operatorname{TUC}_{0}\left(T_{1}, T_{2}\right)=\frac{1}{T}\left\{O R+H O_{O W}+S C+L S+I T_{0}\right\}, \\
T \operatorname{TUC}_{0}\left(T_{1}, T_{2}\right)=\frac{1}{T}\left\{A+H\left(\frac{T_{1}^{2}}{2}+\frac{b T_{1}^{3}}{3}-\frac{r T_{1}^{3}}{6}-\frac{b r T_{1}^{4}}{8}+\frac{\alpha \beta T_{1}^{\beta+2}}{(\beta+1)(\beta+2)}-\frac{b \alpha T_{1}^{\beta+3}}{(\beta+1)(\beta+3)}\right)\right. \\
+s a\left[\frac{\left(1-r T_{1}\right) T_{2}^{2}}{2}-\frac{r T_{2}^{3}}{3}\right]+\pi a \lambda\left\{\frac{\left(1-r T_{1}\right) T_{2}^{2}}{2}-\frac{r T_{2}^{3}}{3}\right\} \\
\left.+C\left[W+a T_{2}\left(1-r\left(T_{1}+T_{2}\right)\right)\right]\right\} .
\end{gathered}
$$

In the above expression, $T U C_{0}$ is the objective function which we have to minimize, which is the function of $T_{1}$ and $T_{2}$. To minimize the objective function, the solution methodology is presented in Section 6.

\section{Solution Procedure}

To derive the optimal solutions, the following classical optimization technique was used.

Step 1. Take the partial derivatives of $\operatorname{TUC}\left(T_{1}, T_{2}, T_{3}\right)$ with respect to $T_{1}, T_{2}$, and $T_{3}$ and equate the results to zero. The necessary conditions for optimality are

$$
\frac{\partial T U C\left(T_{1}, T_{2}, T_{3}\right)}{\partial T_{1}}=0, \quad \frac{\partial T U C\left(T_{1}, T_{2}, T_{3}\right)}{\partial T_{2}}=0, \quad \frac{\partial T U C\left(T_{1}, T_{2}, T_{3}\right)}{\partial T_{3}}=0 .
$$


Step 2. The simultaneous equations above can be solved for $T_{1}^{*}, T_{2}^{*}$, and $T_{3}^{*}$.

Step 3. With $T_{1}^{*}, T_{2}^{*}$, and $T_{3}^{*}$ found in Step 2, derive $T U C^{*}\left(T_{1}^{*}, T_{2}^{*}, T_{3}^{*}\right)$.

\section{Numerical Example}

Optimal replenishment policy to minimize the total present value cost is derived by using the methodology given in the preceding section. The following parameters are assumed: $a=$ $400, b=0.05$, ordering cost $=100$, holding cost in $O W=2$, holding cost in $R W=25$, shortage $\cos t=25$, lost sale cost $=10$, item cost $=10$, inflation rate $=0.06$, own warehouse capacity $=100$, fraction backordered $=0.8$, and the deterioration parameters $\alpha=0.05, \beta=1.8, g=$ 0.02 , and $h=1.8$.

From the below Table 1 and Figure 5, the main observations drown from the numerical example are as follows:

For Model 1

(1) From Table 1, when all the given conditions and constraints are satisfied, the optimal solution is found. In this example, the minimal value of the total present value cost per unit time is $\$ 1006.31$, while the respective optimal values of $T_{1}^{*}, T_{2}^{*}, T_{3}^{*}$, and $T^{*}$ are $0.53,4.31,3.41$, and 8.25 , respectively.

(2) When there is only rented warehouse, the minimal value of the total present value cost per unit time is $\$ 2112.41$, while the respective optimal period of positive and negative inventory levels are 0.04 and 0.11 , respectively.

(3) When there is only own warehouse with fixed capacity $W$ units, the minimal value of the total present value cost per unit time is $\$ 3378.63$, while the respective optimal periods of positive and negative inventory levels are 5.52 and 3.67, respectively. The system has no space to store excess unit and its TUC is higher than our example due to holding cost and shortage cost.

For Model 2

(1) From Table 1, when all the given conditions and constraints are satisfied, the optimal solution is found. In this example, the minimal value of the total present value cost per unit time is $\$ 1786.38$, while the respective optimal values of $T_{1}{ }^{*}, T_{2}{ }^{*}, T_{3}{ }^{*}$, and $T^{*}$ are $0.67,6.42,4.11$, and 11.20 , respectively.

(2) When there is only rented warehouse, the minimal value of the total present value cost per unit time is $\$ 3755.68$, while the respective optimal periods of positive and negative inventory levels are 0.58 and 0.12 , respectively.

(3) When there is only own warehouse with fixed capacity $W$ units, the minimal value of the total present value cost per unit time is $\$ 5302.62$, while the respective optimal periods of positive and negative inventory levels are 6.27 and 4.23 , respectively. The system has no space to store excess unit and its TUC is higher than our example due to holding cost and shortage cost.

\section{For Model 3}

(1) From Table 1, when all the given conditions and constraints are satisfied, the optimal solution is found. In this example, the minimal value of the total present 
Table 1: Comparison of models with different demand patterns.

\begin{tabular}{|c|c|c|c|c|c|c|}
\hline Model & Demand & Warehouse & $T_{1}$ & $T_{2}$ & $T_{3}$ & TUC \\
\hline \multirow{3}{*}{ I } & \multirow{3}{*}{$\begin{array}{l}\text { Exponential } \\
\text { increasing demand } \\
\text { rate, that is, } a e^{b t}\end{array}$} & Two warehouses & 0.53 & 4.31 & 3.41 & 1006.31 \\
\hline & & One warehouse (rented) & 0.04 & 0.11 & - & 2112.41 \\
\hline & & One warehouse (own) & 5.52 & 3.67 & - & 3378.63 \\
\hline \multirow{3}{*}{ II } & \multirow{3}{*}{$\begin{array}{l}\text { Linearly increasing } \\
\text { demand rate, that is, } \\
a+b t\end{array}$} & Two warehouses & 0.67 & 6.42 & 4.11 & 1786.38 \\
\hline & & One warehouse (rented) & 0.58 & 0.12 & - & 3755.68 \\
\hline & & One warehouse (own) & 6.27 & 4.23 & - & 5302.62 \\
\hline \multirow{3}{*}{ III } & \multirow{3}{*}{$\begin{array}{l}\text { Constant demand } \\
\text { rate }(a)\end{array}$} & Two warehouses & 0.82 & 9.49 & 5.06 & 2506.38 \\
\hline & & One warehouse (rented) & 0.09 & 0.13 & - & 4912.22 \\
\hline & & One warehouse (own) & 8.52 & 5.76 & - & 6078.92 \\
\hline
\end{tabular}

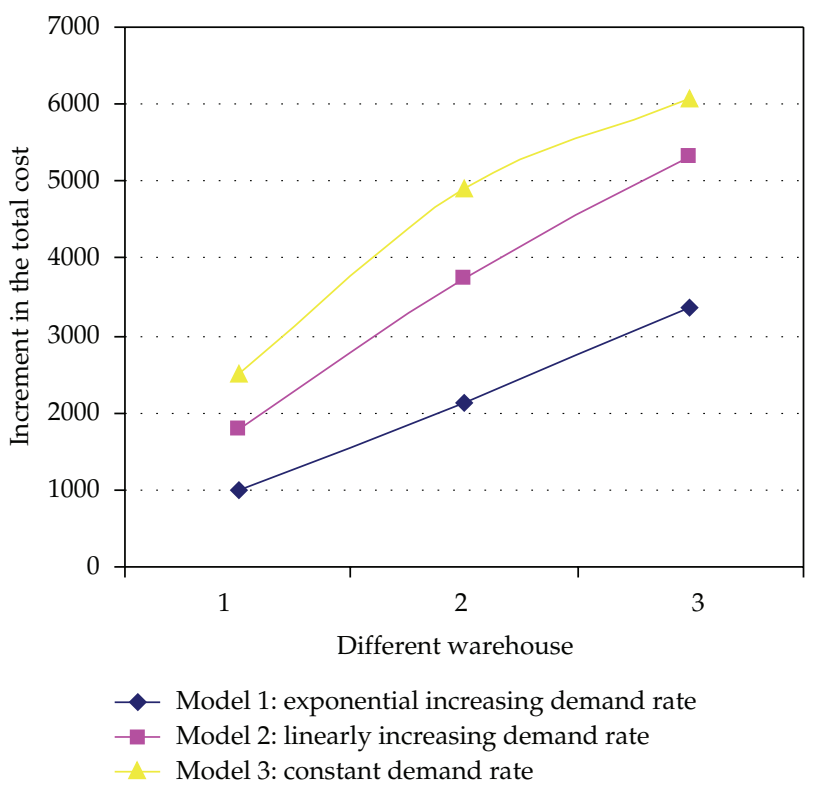

Figure 5: Graphical representation of total cost for different demand rates.

value cost per unit time is $\$ 2506.38$, while the respective optimal values of $T_{1}^{*}, T_{2}{ }^{*}, T_{3}^{*}$, and $T^{*}$ are $0.82,9.49,5.06$, and 15.30 , respectively.

(2) When there is only rented warehouse, the minimal value of the total present value cost per unit time is $\$ 4912.22$, while the respective optimal periods of positive and negative inventory levels are 0.09 and 0.13 , respectively.

(3) When there is only own warehouse with fixed capacity $W$ units, the minimal value of the total present value cost per unit time is $\$ 6078.92$, while the respective optimal periods of positive and negative inventory levels are 8.52 and 5.76, respectively. The system has no space to store excess unit and its TUC is higher than our example due to holding cost and shortage cost. 
Table 2: The sensitivity analysis data showing various parameters.

\begin{tabular}{|c|c|c|c|c|c|c|}
\hline Parameter & $\%$ & $T_{1}$ & $T_{2}$ & $T_{3}$ & TUC & PCI (\%) \\
\hline \multirow{4}{*}{$W$} & 20 & 0.52 & 4.35 & 3.38 & 1015.31 & 0.89 \\
\hline & 10 & 0.52 & 4.32 & 3.40 & 1010.06 & 0.37 \\
\hline & -10 & 0.53 & 4.30 & 3.43 & 1002.82 & -0.34 \\
\hline & -20 & 0.53 & 4.28 & 3.44 & 998.74 & -0.72 \\
\hline \multirow{4}{*}{$r$} & 20 & 0.23 & 3.67 & 2.97 & 384.75 & -61.76 \\
\hline & 10 & 0.41 & 4.01 & 3.48 & 658.76 & -34.53 \\
\hline & -10 & 0.73 & 4.98 & 5.03 & 1349.81 & 34.14 \\
\hline & -20 & 0.92 & 5.67 & 5.98 & 1643.78 & 63.34 \\
\hline \multirow{4}{*}{$\alpha$} & 20 & 0.60 & 4.04 & 3.58 & 1921.46 & 90.94 \\
\hline & 10 & 0.57 & 4.21 & 3.49 & 1435.53 & 42.65 \\
\hline & -10 & 0.48 & 4.67 & 3.20 & 800.69 & -20.43 \\
\hline & -20 & 0.43 & 5.32 & 3.18 & 506.23 & -49.69 \\
\hline \multirow{4}{*}{$\beta$} & 20 & 0.73 & 2.46 & 4.25 & 2365.46 & 135.06 \\
\hline & 10 & 0.63 & 3.21 & 3.80 & 1686.47 & 67.58 \\
\hline & -10 & 0.38 & 4.67 & 3.03 & 754.87 & -24.98 \\
\hline & -20 & 0.27 & 5.09 & 2.68 & 456.23 & -54.66 \\
\hline \multirow{4}{*}{$g$} & 20 & 0.52 & 4.31 & 3.41 & 1006.96 & 0.06 \\
\hline & 10 & 0.53 & 4.31 & 3.41 & 1006.75 & 0.04 \\
\hline & -10 & 0.53 & 4.31 & 3.41 & 1005.86 & -0.04 \\
\hline & -20 & 0.54 & 4.31 & 3.41 & 1005.68 & -0.06 \\
\hline \multirow{4}{*}{$h$} & 20 & 0.53 & 4.31 & 3.41 & 1006.96 & 0.06 \\
\hline & 10 & 0.53 & 4.31 & 3.41 & 1006.75 & 0.04 \\
\hline & -10 & 0.53 & 4.31 & 3.41 & 1005.86 & -0.04 \\
\hline & -20 & 0.53 & 4.31 & 3.41 & 1005.68 & -0.06 \\
\hline
\end{tabular}

\section{Sensitivity Analysis}

In order to study how the parameters affect the optimal solution, the sensitivity analysis is carried out with respect to the various parameters. The results of the sensitivity analysis are presented in Table 2, Figure 6 and Figure 7.

The main observations drawn from the sensitivity analysis are as follows:

(1) the value of PCI is the most sensitive to the shape parameter $(\beta)$ of the deterioration rate and the inflation rate $(r)$. When $\beta$ increases by $20 \%$, the value of PCI increases by over $135 \%$. When $r$ increases by $20 \%$, the value of PCI decreases by over $61 \%$.

(2) the values of PCI are quite sensitive to the parameters $\alpha$ and are not so sensitive to the parameters $h, g$, and $W$.

(3) the parameters $\alpha, \beta, g, h, W$, and $B$ increase proportional to the value of PCI. The $\mathrm{PCI}$ is inversely proportional to the parameters $r$.

(4) a high parameter value of $\beta$ results in a high value of $T_{1}$ and $T_{3}$. A high parameter value of $\mathrm{r}$ results in a small value of $T_{1}, T_{2}$, and $T_{3}$. 


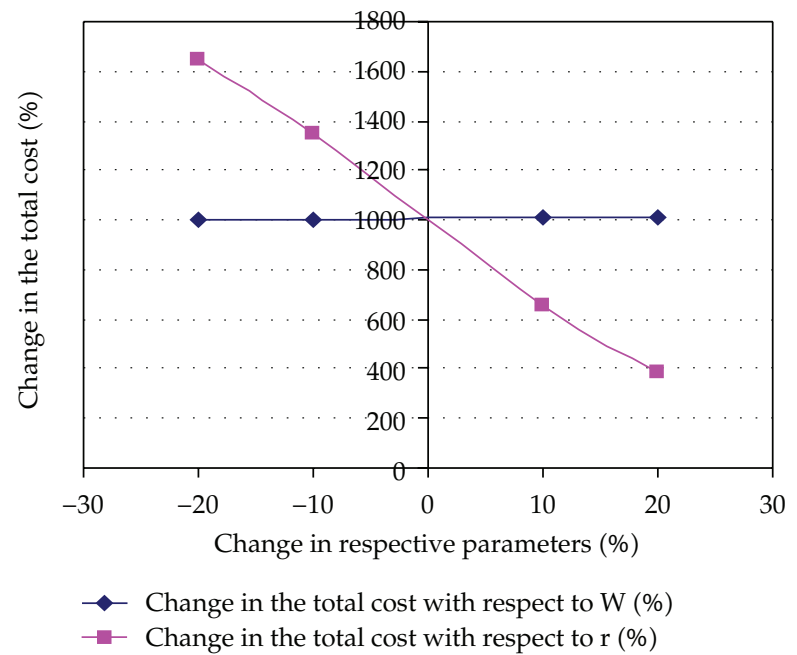

Figure 6: Percentage change in the total cost with respect to the parameters $W$ and $r$.

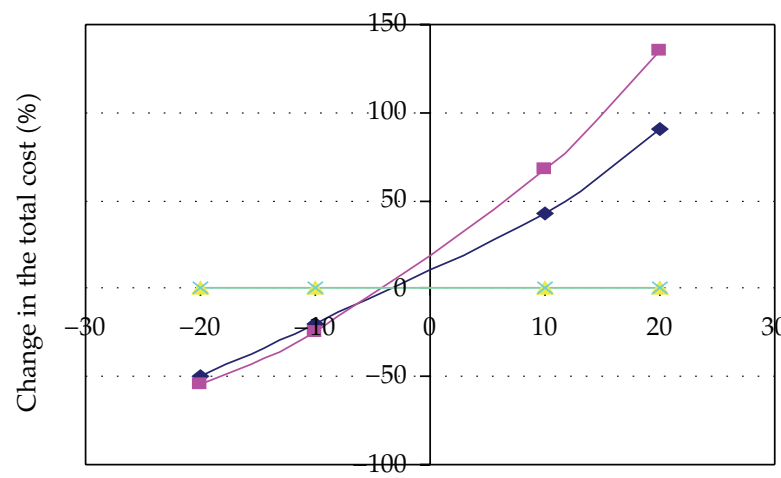

Change in respective parameters (\%)

- Change in the total cost with respect to $\alpha(\%)$

$\rightarrow$ Change in the total cost with respect to $\beta(\%)$

- Change in the total cost with respect to $g(\%)$

$\star$ Change in the total cost with respect to $\mathrm{h}(\%)$

Figure 7: Percentage change in the total cost with respect to the parameters $\alpha, \beta, g$, and $h$.

\section{Conclusion}

In this study, an inventory model is presented to determine the optimal replenishment cycle for two-warehouse inventory problem under inflation, varying rate of deterioration, and partial backordering. The model assumes limited warehouse's capacity of the distributors. Here, shortages are allowed and partially backlogged. The holding cost at $R W$ is higher as compared to $O W$. The rate of deterioration in both warehouses is different and follows a two-parameter Weibull distribution. The DCF approach permits a proper recognition of the financial implication of the lost sale in inventory analysis. Some items such as fashionable goods, luxury items, and electronic products are easily identifiable with such kind of a setup, the demand rate is exponentially increasing with time and shortages are allowed and partially 
backlogged with exponential backlogging rate. The discounted cash flow (DCF) and classical optimization technique are used to derive the optimal replenishment policy. A numerical example and sensitivity analysis are implemented to illustrate the model with the help of MATHEMATICA-5.2. When there is only rented or own warehouse in the inventory system, the total present values of the total relevant cost per unit time are higher than the twowarehouse model. From the numerical example, we could finally conclude that model 1 is more profitable in comparison to model 2 and model 3 for two-warehouse inventory system. As the backlogging and deterioration rate increases, the total cost of the system also increases. But as the inflation rate increases, the total cost of the system decreases. From the sensitivity analysis, it is evident that the deterioration rate, the inflation, and the backordering rate affect the total cost of the system. In order to optimize the system, the decision maker must develop the most economical replenishment strategy.

There is ample scope for further extension of the present research study in fuzzy environments, trade credits, and situations of stock-dependent demand.

\section{Acknowledgment}

The authors wish to thank the referees for their constructive comments and suggestions on the earlier version of the paper.

\section{References}

[1] R. V. Hartely, Operations Research-A Managerial Emphasis, Good Year Publishing Company, 1976.

[2] K. V. S. Sarma, "A deterministic order level inventory model for deteriorating items with two storage facilities," European Journal of Operational Research, vol. 29, no. 1, pp. 70-73, 1987.

[3] T. P. M. Pakkala and K. K. Achary, "A deterministic inventory model for deteriorating items with two warehouses and finite replenishment rate," European Journal of Operational Research, vol. 57, no. 1, pp. 71-76, 1992.

[4] L. Benkherouf, "A deterministic order level inventory model for deteriorating items with two storage facilities," International Journal of Production Economics, vol. 48, no. 2, pp. 167-175, 1997.

[5] A. K. Bhunia and M. Maiti, "A two warehouse inventory model for deteriorating items with a linear trend in demand and shortages," Journal of the Operational Research Society, vol. 49, no. 3, pp. 287-292, 1998.

[6] J. A. Buzacott, "Economic order quantities with inflation," Operational Research Quarterly, vol. 26, no. 3, pp. 553-558, 1975.

[7] R. B. Misra, "A note on optimal inventory management under inflation," Naval Research Logistics, vol. 26, no. 1, pp. 161-165, 1979.

[8] M. J. Chandra and M. L. Bahner, "The effects of inflation and the time value of money on some inventory systems," International Journal of Production Research, vol. 23, no. 4, pp. 723-730, 1985.

[9] B. R. Sarker and H. Pan, "Effects of inflation and the time value of money on order quantity and allowable shortage," International Journal of Production Economics, vol. 34, no. 1, pp. 65-72, 1994.

[10] M. A. Hariga, "Effects of inflation and time-value of money on an inventory model with timedependent demand rate and shortages," European Journal of Operational Research, vol. 81, no. 3, pp. 512-520, 1995.

[11] S. Bose, S. B. Goswami, and K. S. Chaudhuri, "An EOQ model for deteriorating items with linear timedependent demand rate and shortages under inflation and time discounting," Journal of the Operational Research Society, vol. 46, no. 6, pp. 771-782, 1995.

[12] C. Van Delft and J. P. Vial, "Discounted costs, obsolescence and planned stockouts with the EOQ formula," International Journal of Production Economics, vol. 44, no. 3, pp. 255-265, 1996.

[13] I. Moon and S. Lee, "The effects of inflation and time-value of money on an economic order quantity model with a random product life cycle," European Journal of Operational Research, vol. 125, no. 3, pp. 588-601, 2000. 
[14] H.-L. Yang, "Two-warehouse inventory models for deteriorating items with shortages under inflation," European Journal of Operational Research, vol. 157, no. 2, pp. 344-356, 2004.

[15] H. M. Wee, J. C. P. Yu, and S. T. Law, "Two-warehouse inventory model with partial backordering and Weibull distribution deterioration under inflation," Journal of the Chinese Institute of Industrial Engineers, vol. 22, no. 6, pp. 451-462, 2005.

[16] H. L. Yang, "Two-warehouse partial backlogging inventory models for deteriorating items under inflation," International Journal of Production Economics, vol. 103, no. 1, pp. 362-370, 2006.

[17] J. K. Dey, S. K. Mondal, and M. Maiti, "Two storage inventory problem with dynamic demand and interval valued lead-time over finite time horizon under inflation and time-value of money," European Journal of Operational Research, vol. 185, no. 1, pp. 170-194, 2008.

[18] S. Ghosh and T. Chakrabarty, "An order-level inventory model under two level storage system with timedependent demand," OPSEARCH, vol. 46, no. 3, pp. 335-344, 2009.

[19] C. K. Jaggi and P. Verma, "Two-warehouse inventory model for deteriorating items with linear trend in demand and shortages under inflationary conditions," International Journal of Procurement Management, vol. 3, no. 1, pp. 54-71, 2010.

[20] S. K. Patra, "Two-warehouse inventory model for deteriorating items: a study with shortages under inflation and time value of money," International Journal of Services and Operations Management, vol. 10, no. 3, pp. 316-327, 2011.

[21] S. R. Singh, R. Kumari, and N. Kumar, "A deterministic two warehouse inventory model for deteriorating items with stock-dependent demand and shortages under the conditions of permissible delay," International Journal of Mathematical Modelling and Numerical Optimisation, vol. 2, no. 4, pp. 357375, 2011.

[22] H.-L. Yang, "Two-warehouse partial backlogging inventory models with three-parameter Weibull distribution deterioration under inflation," International Journal of Production Economics, vol. 138, no. 1, pp. 107-116, 2012. 


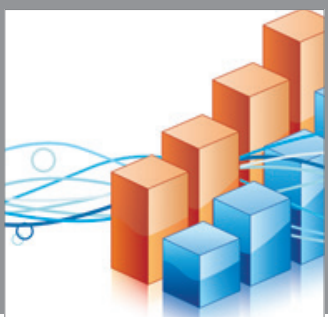

Advances in

Operations Research

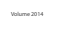

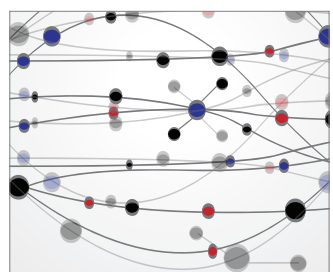

\section{The Scientific} World Journal
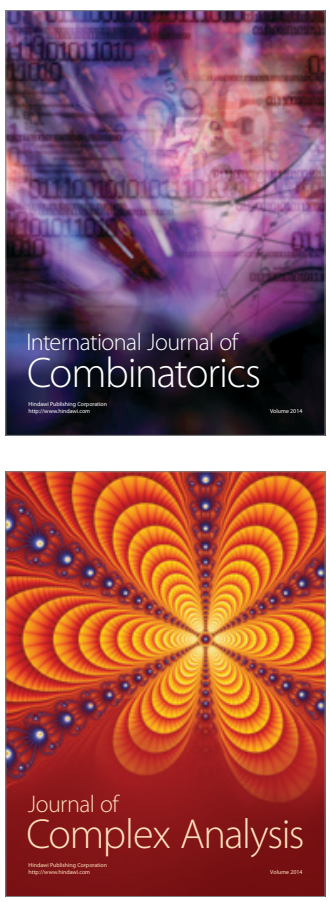

International Journal of

Mathematics and

Mathematical

Sciences
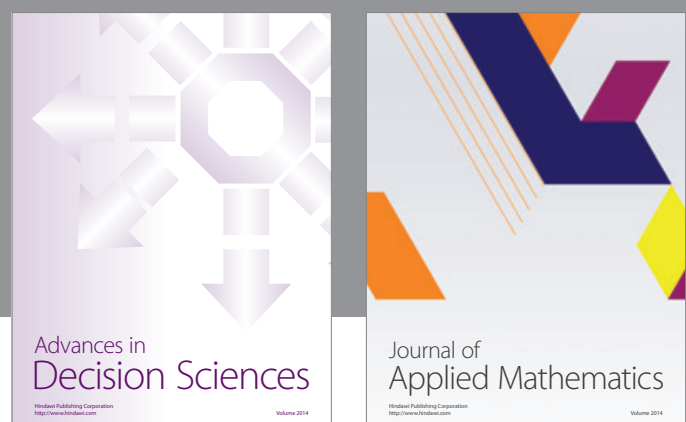

Journal of

Applied Mathematics
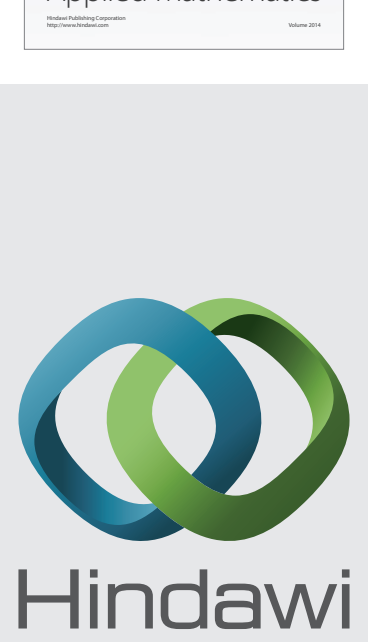

Submit your manuscripts at http://www.hindawi.com
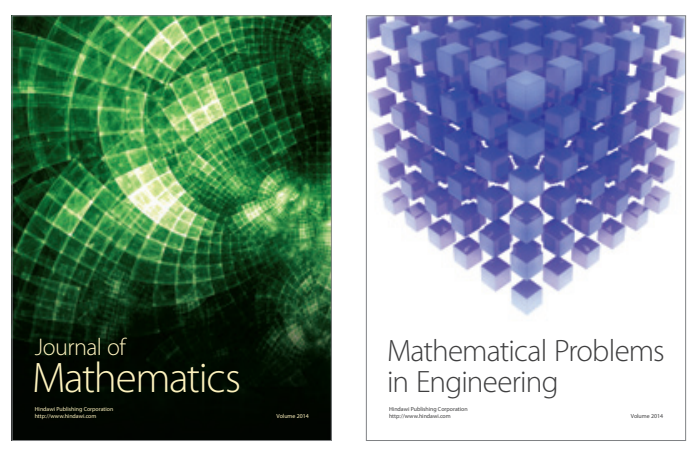

Mathematical Problems in Engineering
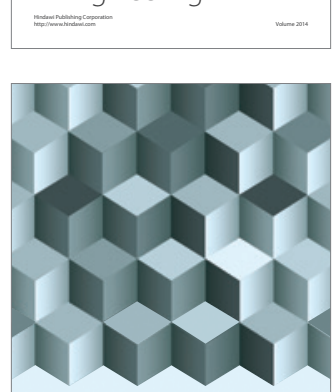

Journal of

Function Spaces
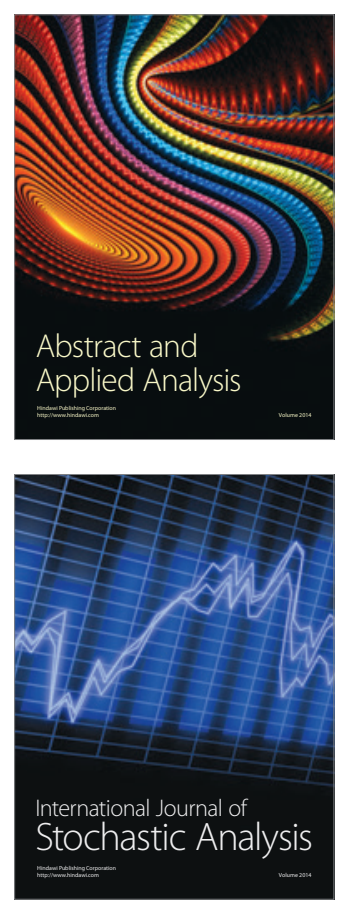

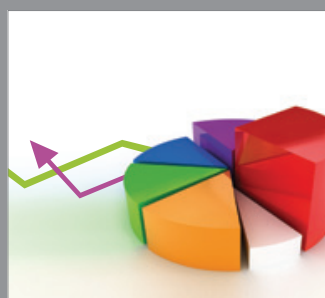

ournal of

Probability and Statistics

Promensencen
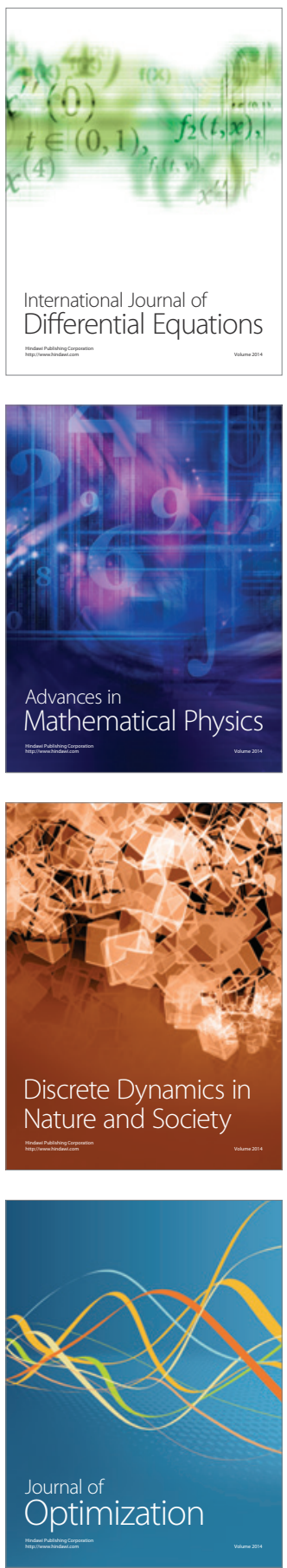